\title{
Characterization of a Chicken Embryo-Adapted H9N2 Subtype Avian Influenza Virus
}

\author{
Hyuk-Joon Kwon ${ }^{*}, 1$, Sun-Hee $\mathrm{Cho}^{2}$, Young-Jin $\mathrm{Ahn}^{2}$, Jae-Hong Kim ${ }^{1,2}$, Han-Sang Yoo ${ }^{1,2}$ and \\ Sun-Joong Kim ${ }^{1,2}$
}

\author{
${ }^{1}$ Zoonotic Disease Institute (ZooDI), Seoul National University, Seoul 151-742, Republic of Korea \\ ${ }^{2}$ College of Veterinary Medicine and BK21 for Veterinary Science, Seoul National University, Seoul 151-742, Republic \\ of Korea
}

\begin{abstract}
The low pathogenic avian influenza (LPAI) caused by H9N2 virus has generated economic losses in the Korean poultry industry since 1999, but field isolates could not be used for killed oil emulsion vaccine directly because of low productivity in embryonated chicken eggs (ECE). Therefore, we established a vaccine strain, KBNP-0028, by passage through ECE with allantoic fluid showing the highest volume and titer. KBNP-0028 possessed $158 \mathrm{~N}$-glycan on hemagglutinin (HA) as its parent strain, but acquired a 16 amino acid deletion in the stalk region of neuraminidase (16-del NA) as a result of balancing with the glycosylated HA. KBNP-0028 was sufficiently productive in ECE to be compared with the A/Puerto Rico/8/34 (PR8) strain and immunogenic enough to induce high antibody titers. The antibodies inhibited hemagglutination of recent field isolates as highly as they inhibited KBNP-0028. Genome analysis revealed that KBNP0028 carried no known mutation relevant to virulence in mammalian. In conclusion, KBNP-0028 is a promising vaccine candidate for prevention of the LPAI in the Republic of Korea.
\end{abstract}

Keywords: Low pathogenic avian influenza vaccine, H9N2, balancing, stalk deletion, genome sequencing.

\section{INTRODUCTION}

Influenza viruses are enveloped, segmented, singlestranded, negative-sense RNA viruses of the family Orthomyxoviridae, and are divided into types A, B, and C. Influenza A viruses are further divided into 16 hemagglutinin (HA) and 9 neuraminidase (NA) subtypes. Wild aquatic birds serve as the reservoirs of all known subtypes [1,2].

$\mathrm{H} 9$ subtypes of the avian influenza virus (AIV) have been isolated infrequently, but became globally prevalent in domestic poultry in the 1990s [3-8]. The first outbreak of low pathogenic avian influenza caused by H9N2 virus (LPAI) in 1996 in the Republic of Korea prompted an eradication response, and LPAI was controlled until re-isolation of H9N2 viruses in $1999[9,10]$. Since then, it has become enzootic, and has caused economic losses due to egg drops and occasional mortality [11, 12].

H9N2 viruses show variation in their replication efficiencies in embryonated chicken eggs (ECE) [13]. A/Quail/Hong Kong/G1/97 replicated to high titer, but low passage A/Chicken/Hong Kong/G9/97 failed to result in a high titer in ECE. Vaccine efficacy is dependent on the amount of antigen present, and in an attempt to develop the G9 virus as a vaccine strain, a reassortant virus with its own $H A$ and $N A$ in the backgrounds of other six genes derived from the A/Puerto Rico/8/34 (PR8) strain which grew to high titer in ECE was generated [13]. The rate of early embryonic death,

*Address correspondence to this author at the Laboratory of Influenza Virus, Zoonotic Disease Institute (ZooDI), Seoul National University, San 561, Shillim-Dong, Gwanak-Gu, Seoul 151-742, Republic of Korea; Tel: 82-2880-1288; Fax: 82-2-885-6614; E-mail: kwonhj01@ snu.ac.kr namely the virulence to chicken embryos, is one of the categories for evaluation of influenza vaccine candidates. The World Health Organization (WHO) recommends selecting a human vaccine candidate that causes less than $20 \%$ embryonic chicken mortality within 3 days after virus inoculation, and the World Organization for Animal Health (OIE) recommends that the ECE which died within 24 hrs after inoculation should not be used for animal vaccine production. Therefore, a vaccine candidate that causes early embryonic death does not meet with world standards, and its productivity is also likely to be very low $[14,15]$. Korean field isolates are less productive in ECE, and their productivities should be improved prior to use in vaccine development $[9,16,17]$. The efficiency of influenza virus replication in ECE can be affected by the receptor affinity of HA, the balance of HA and NA activities, and internal genes [13, 18-23]. A good vaccine candidate should be cost-effective in production, antigenically representative of contemporary field strains, and safe for chickens and mammals. The virulence of AIV to chickens is mainly determined by the number of basic amino acids at the proteolytic cleavage site of HA, while the ability of AIV to overcome the host barrier for mammalian infection is a multigenic trait. The shift of receptor binding affinity of HA from 5-N-acetylneuraminic acid- $\alpha 2,3$-galactose (Neu5Ac- $\alpha 2,3-\mathrm{Gal}$, avian) to Neu5Ac- $\alpha 2,6-\mathrm{Gal}$ (human) is a critical step in the overcoming of the host barrier [19]. D92E and E627K mutations of nonstructural protein 1 (NS1) and basic polymerase 2 (PB2), respectively, may increase the virulence of $\mathrm{H} 5 \mathrm{~N} 1$ influenza $\mathrm{A}$ virus to humans and mice [24-26]. Recently, a novel conserved 87-residue protein, PB1-F2, was reported to function to kill host immune cells responding to AIV infection [27]. PDZ domains bind to specific short C-terminal or internal peptides and they are fre- 
quently found in scaffold proteins that perform localized signaling functions at particular subcellular locations and may also be involved in the trafficking of interacting proteins within the cell [28]. A PDZ domain ligand (PL) was newly identified at the $\mathrm{C}$ terminus of NS1. The C terminal PL of NS1 in low-pathogenic human influenza viruses had no interaction with PDZ domains, while the highly pathogenic viruses were all able to interact with some of the PDZ domains [29]. Resistance to antiviral agents is among the risks to be considered, and V27A, A30S, and S31N mutations in M2 are related to amantadine resistance [30]. In the present study, we aimed to develop a productive vaccine candidate to control LPAI caused by H9N2 viruses in the Republic of Korea. To achieve this, we passaged a field strain, SNU0028, through ECE 19 times, and established a vaccine candidate for a killed oil emulsion vaccine, KBNP0028. We characterized some important biological traits of the vaccine candidate and analyzed the full genomic sequence of the virus.

\section{MATERIALS AND METHODS}

\section{Viruses}

Influenza viruses, SNU0028, KBNP-0028 [a progeny virus of SNU0028 passaged through SPF embryonated chicken eggs (ECE) 19 times], PR8, SNU5011, SNU5012, and SNU5022 were propagated in the allantoic cavity of 10day-old embryonated SPF chicken eggs (ECE; Hy-Vac, Adel, Iowa). SNU0028 was isolated from diseased broiler breeder in 2000 [31], and SNU5011, SNU5012, and SNU5022 were isolated from diseased layers of geographically and epizootiologically unrelated farms in 2005.

\section{Generation of KBNP-0028 and Antisera}

Five 10-day-old ECE were inoculated with $10^{4}$-fold diluted allantoic fluid of SNU0028, candled twice a day for three days, and chilled at $4{ }^{\circ} \mathrm{C}$. ECE that died within three days were discarded. We measured the amount of allantoic fluid and hemagglutination units for each sample and chose the sample that was most abundant in amount and highest in haemagglutination (HA) titer for the next passage. The HA test was conducted as described previously [14]. We repeated the same procedure 19 times, and the resulting virus was named KBNP-0028.
Anti-KBNP-0028 chicken antisera were produced in five 6-week-old SPF chickens by inoculation of $500 \mu \mathrm{l}$ of oil emulsion vaccine that had been emulsified with equal volumes of formalin-inactivated infectious allantoic fluid and incomplete Freund's adjuvant (GIBCO BRL, Invitrogen). Positive serum was prepared by mixing the field serum samples which shows high HI titer (>64), and negative serum was prepared from SPF chickens.

\section{Productivity and Pathogenicity of KBNP-0028 in ECE}

Ten-day-old SPF ECE were inoculated with 0.1 hemagglutination unit (HAU) of SNU0028-E5, KBNP-0028 and PR8 strains via allantoic cavity (AC), and the HAUs and the amount of each allantoic fluid were subsequently measured (Table 1). To measure the $50 \%$ embryo infective dose $\left(\mathrm{EID}_{50}\right)$ of KBNP-0028, the infectious allantoic fluid was serially diluted with phosphate-buffered saline (PBS) by tenfold, and $200 \mu l$ of each diluted allantoic fluid was inoculated into five ECE via the AC route. The $\mathrm{EID}_{50}$ was calculated using the Reed-Muench formula. As repeats of embryonic mortality test, 120 and 107 ECE were inoculated with $200 \mu l$ of KBNP-0028 and incubated for three days with candling twice a day.

\section{Immunogenicity of KBNP-0028}

The immunogenicity of KBNP-0028 was assessed with an $\mathrm{HI}$ test employing chicken polyclonal antisera against antigen KBNP-0028 and antigens, KBNP-0028, SNU5011, SNU5012, and SNU5022, as described previously [14]. The titers were expressed as reciprocals of the highest dilution of antisera that caused complete inhibition of agglutination, and the median titer was represented.

\section{RT-PCR, Sequencing, and Sequence Analysis}

Eight amplicons encompassing the segmented genomes of KBNP-0028 were obtained via RT-PCR as described previously [32], and were then cloned into the Topo-TA cloning vector in accordance with the protocol of the manufacturer (Invitrogen, USA). RNA isolation and RT-PCR were conducted as described previously [32]. M13 forward and reverse primers were used for sequencing, and additional sequencing primers were designed on the basis of the determined sequences: 0028-PB1-697, gagcactgac tttgaacac; 0028-PB2-713, aagcagcgta tacattgagg; 0028-PA-733, atgtggatgg attgaaccg; 0028-HA-729, aggcctcctg tcaatggtc; 0028-NP-

Table 1. Comparison of KBNP-0028 (SNU0028-E20) with an Early Passage Virus (SNU0028-E5)

\begin{tabular}{|c|c|c|c|c|c|c|}
\hline & & SNU0028-E5 & PR8 & \multicolumn{3}{|c|}{ KBNP-0028 } \\
\hline \multicolumn{2}{|c|}{ No. of $E_{C E}^{a}$} & 15 & 15 & 15 & 107 & 120 \\
\hline \multirow{2}{*}{ Embryonic mortality } & $24 \mathrm{hrs}^{\mathrm{b}}$ & $46.7 \%^{\mathrm{c}}$ & $6.7 \%^{\mathrm{c}}$ & $6.7 \%^{\mathrm{c}}$ & $\mathrm{nd}^{\mathrm{d}}$ & nd \\
\hline & $72 \mathrm{hrs}$ & $46.7 \%$ & $13.3 \%$ & $13.3 \%$ & $15.8 \%$ & $14.1 \%$ \\
\hline \multicolumn{2}{|c|}{ Total HAU ${ }^{\mathrm{e}}$} & $1,725,440$ & $3,778,560$ & $2,923,520$ & nd & nd \\
\hline \multicolumn{2}{|c|}{ Median HAU/ECE } & 194,560 & 245,760 & 271,360 & nd & nd \\
\hline \multicolumn{2}{|c|}{$\mathrm{EID}_{50}$} & nd & nd & $10^{8.8} / \mathrm{ml}$ & nd & nd \\
\hline
\end{tabular}

${ }^{\mathrm{a}}$ Embryonated chicken egg (ECE).

${ }^{\mathrm{b}}$ Mortality within 24 hours.

${ }^{\mathrm{c}}$ Significant difference between SNU0028-E5 and PR8, and SNU0028-E5 and KBNP-0028 $(P=0.035, P<0.05)$.

${ }^{\mathrm{d}}$ Not Detemined (nd).

${ }^{\mathrm{e}} \mathrm{ECE}$ died within 72 hours were excluded for measurement. 
596, tggtgcagca gtaaagggag. To determine the nucleotide deletion in the stalk region of the NA gene, a primer set was designed based on the nucleotide sequences of KBNP-0028: NAdelF, tcctcatgca grtygcyat; NAdelR, tgrcaytgyg gtttygacc. Nucleotide and deduced amino acid sequences were aligned with the Clustal method in the MegAlign program (Windows version 3.12e: DNASTAR, Madison, WI), and the amino acid sequences of KBNP-0028 were compared with those of influenza viruses in the GenBank via the BLAST search.

\section{Accession Numbers}

All sequences determined in the present study were deposited in the GenBank Data Library under accession numbers EF620897-EF620904, and other sequences examined are also available in the GenBank. These included: HA genes, DQ473608 (SNU0028), AF523379 (Dk/ST/1605/01), AB049159 (Pk/Chi/1/97), AF156378 (Qa/HK/G1/97), AF156376 (Dk/HK/Y280/97), AF156373 (Ck/HK/G9/97), AF156384 (Ck/Kor/96323/96), AF156380 (Ck/BJ/1/94); NA genes, AF523402 (Dk/ST/1605/01), AB049163 (Pk/Chi/1/97), AF156396 (Qa/HK/G1/97), AF156394 (Dk/HK/Y280/97), AF156391 (Ck/HK/G9/97), AF156400 (Ck/Kor/96323/96), AF156398 (Ck/BJ/1/94); NS genes, AF523504 (Dk/ST/1605/01), AB049167 (Pk/Chi/1/97), AF156477, (Qa/HK/G1/97), AF156475 (Dk/HK/Y280/97), AF156472 (Ck/HK/G9/97), AF156481 (Ck/Kor/96323/96), AF156480 (Ck/BJ/1/94); M genes, AF523493 (Dk/ST/1605/01), AB049165 (Pk/Chi/1/97), AF156463 (Qa/HK/G1/97), AF156461 (Dk/HK/Y280/97), AF156458 (Ck/HK/G9/97), AF156467 (Ck/Kor/96323/96), AF156466 (Ck/BJ/1/94); PB2 genes, AY768575 (SNU0028), AF523471 (Dk/ST/1605/01), AB049153 (Pk/Chi/1/97), AF156435 (Qa/HK/G1/97), AF156433 (Dk/HK/Y280/97), AF156430 (Ck/HK/G9/97), AF156439 (Ck/Kor/96323/96), AF156438 (Ck/BJ/1/94); PB1 genes, AF523442 (Dk/ST/1605/01), AB049155 (Pk/Chi/1/97), AF156421 (Qa/HK/G1/97), AF156419 (Dk/HK/Y280/97), AF156416 (Ck/HK/G9/97), AF156425 (Ck/Kor/96323/96), AF156423 (Ck/BJ/1/94); PA genes, AB049157 (Pk/Chi/1/97), AF156449 (Qa/HK/G1/97), AF156447 (Dk/HK/Y280/97), AF156444 (Ck/HK/G9/97), AF156453 (Ck/Kor/96323/96), AF156452 (Ck/BJ/1/94); NP genes, AF523414 (Dk/ST/1605/01), AB049161 (Pk/Chi/1/97), AF156407 (Qa/HK/G1/97), AF156405 (Dk/HK/Y280/97), AF156402 (Ck/HK/G9/97), AF156411 (Ck/Kor/96323/96), AF156409 (Ck/BJ/1/94).

\section{Statistical Analysis}

The difference between the mean HA titer for KBNP0028 and that of PR8 was compared using the Student's t- test, and the difference between the frequency of early embryonic death caused by SNU0028-E5 versus that caused by KBNP-0028 was evaluated via chi-square and Fisher's exact tests (95\% confidence interval) using SPSS for Windows ver. 12.0 .

\section{RESULTS}

\section{Productivity and Pathogenicity of KBNP-0028 in ECE}

The mortalities within 24- and 72-hrs, total HAU, median HAU/ECE, and EID $_{50}$ were summarized in Table $\mathbf{1}$. SNU0028-E5, PR8 and KBNP-0028 caused 46.7\%, $6.7 \%$ and $6.7 \%$ of embryonic death within $24 \mathrm{hrs}$, and $46.7 \%$, $13.3 \%$ and $13.3 \%-15.8 \%$ of embryonic death within $72 \mathrm{hrs}$, respectively (Table $\mathbf{1}$ ). The mortality within 72-hrs was not significantly different, but the mortality within 24-hrs was significantly different between SNU0028-E5 and KBNP0028 strains $(P=0.035)$. All of the dead embryos were HApositive. The total HAU of SNU0028-E5, PR8 and KBNP0028 strains were $1,725,440,3,778,560$ and 2, 923, 520, respectively, and the median HAU/ECE were 194, 560, 245, 760 and 271, 360, respectively. The $\mathrm{EID}_{50}$ reached to $10^{8.8} / \mathrm{ml}$ (Table 1).

\section{Immunogenicity of KBNP-0028}

The antisera against KBNP-0028 reacted with recent field isolates of H9N2 viruses, SNU5011, SNU5012, and SNU5022, and their HI titers ranged from 256-4, 096, 256-4, 096, and 1, 024-4, 096, respectively, at 4 weeks post vaccination (Table 2). Antisera 1, 4, and 5 inhibited hemagglutinations of all tested viruses efficiently but antisera 2 and 3 inhibited hemagglutinations of SNU5011, SNU5012 and SNU5022 by 4 to 16 times less efficiently than KBNP-0028 (Table 2).

\section{Analysis of Nucleotide and Amino Acid Sequences}

The nucleotide and amino acid sequences of KBNP-0028 were compared with those of other H9N2 viruses, Dk/ST/1605/01, Pk/Chi/1/97, Qa/HK/G1/97, Dk/HK/Y280/ 97, Ck/HK/G9/97, Ck/Kor/96323/96, and Ck/BJ/1/94 (Table $3)$. The ranges of the percent nucleotide similarity were 80.7 95.7 (HA), 84.5-92.0 (NA), 64.2-94.7 (NS1), 78.3-95.7 (NS2), 89.9-95.4 (M1), 93.4-96.3 (M2), 89.1-93.0 (NP), 86.5-95.7 (PA), 88.9-97.1 (PB1), 88.5-98.1 (PB1-F2), and 84.4-90.7 (PB2), and those of the percent amino acid similarity were 87.5-96.2 (HA), 86.0-93.2 (NA), 65.9-89.8 (NS1), 77.9-94.1 (NS2), 92.9-97.2 (M1), 88.9-93.3 (M2), 96.7-99.1 (NP), 95.8-97.5 (PA), 96.2-98.4 (PB1), 71.1-95.6 (PB1-F2), and 94.9-97.0 (PB2). Most of the nucleotide sequences of the gene segments were more variable than the amino acid se-

Table 2. Immunogenicity of KBNP-0028

\begin{tabular}{|c|c|c|c|c|c|c|c|}
\hline \multirow{2}{*}{ Strain } & \multicolumn{5}{|c|}{ HI Titers of Anti-KBNP-0028 Antisera } & \multirow{2}{*}{ Positive Serum } & \multirow{2}{*}{ Negative Serum } \\
\cline { 2 - 8 } & $\mathbf{1}$ & $\mathbf{2}$ & $\mathbf{3}$ & $\mathbf{4}$ & $\mathbf{5}$ & \multicolumn{2}{|c|}{64} \\
\hline \hline KBNP-0028 & 2,048 & 4,096 & 4,096 & 4,096 & 4,096 & 64 & $<2$ \\
\hline SNU5011 & 2,048 & 4,096 & 256 & 2,048 & 4,096 & 4,096 & 64 \\
\hline SNU5012 & 2,048 & 512 & 256 & 4,096 & 4,096 & 64 & $<2$ \\
\hline SNU5022 & 4,096 & 1,024 & 1,024 & 2,048 & 2 \\
\hline
\end{tabular}


Table 3. Genetic Relationship of KBNP-0028 with Other Influenza Viruses

\begin{tabular}{|c|c|c|c|c|c|c|c|c|c|c|c|}
\hline \multirow{2}{*}{ Strain } & \multicolumn{11}{|c|}{ \% Nucleotide (Amino Acid) Similarity with KBNP-0028 } \\
\hline & $\begin{array}{c}\text { HA } \\
(10-1207)\end{array}$ & $\begin{array}{c}\text { NA } \\
(\mathbf{1 - 1 3 7 7})\end{array}$ & $\begin{array}{c}\text { NS1 } \\
(5-693)\end{array}$ & $\begin{array}{c}\text { NS2 } \\
(15-221)\end{array}$ & $\begin{array}{c}\text { M1 } \\
(1-759)\end{array}$ & $\begin{array}{c}\text { M2 } \\
(1-271)\end{array}$ & $\underset{(1-999)}{\text { NP }}$ & $\underset{(1-2127)}{\text { PA }}$ & $\begin{array}{c}\text { PB1 } \\
(1-2209)\end{array}$ & $\begin{array}{c}\text { PB1-F2 } \\
(1-270)\end{array}$ & $\begin{array}{c}\text { PB2 } \\
(19-2246)\end{array}$ \\
\hline $\mathrm{Dk} / \mathrm{ST} / 1605 / 01$ & $\begin{array}{c}80.7 \\
(95.2)\end{array}$ & $\begin{array}{c}85.2 \\
(87.1)\end{array}$ & $\begin{array}{c}64.2 \\
(65.9)\end{array}$ & $\begin{array}{c}78.3 \\
(77.9)\end{array}$ & $\begin{array}{c}90.4 \\
(95.3)\end{array}$ & - & $\begin{array}{c}91.3 \\
(99.1)\end{array}$ & - & - & $\begin{array}{c}94.8 \\
(85.6)\end{array}$ & - \\
\hline $\mathrm{Pk} / \mathrm{Chi} / 1 / 97$ & $\begin{array}{c}81.6 \\
(91.2)\end{array}$ & $\begin{array}{c}86.5 \\
(88.3)\end{array}$ & $\begin{array}{c}89.8 \\
(86.3)\end{array}$ & $\begin{array}{c}95.2 \\
(92.6)\end{array}$ & $\begin{array}{c}90.3 \\
(95.3)\end{array}$ & $\begin{array}{c}94.1 \\
(88.9)\end{array}$ & $\begin{array}{c}92.6 \\
(98.8)\end{array}$ & $\begin{array}{c}87.6 \\
(95.9)\end{array}$ & $\begin{array}{c}90.8 \\
(96.6)\end{array}$ & $\begin{array}{c}91.1 \\
(77.8)\end{array}$ & $\begin{array}{c}90.2 \\
(95.4)\end{array}$ \\
\hline $\mathrm{Qa} / \mathrm{HK} / \mathrm{G} 1 / 97$ & $\begin{array}{c}81.6 \\
(96.2)\end{array}$ & $\begin{array}{c}84.5 \\
(86.0)\end{array}$ & $\begin{array}{c}89.8 \\
(86.3)\end{array}$ & $\begin{array}{c}94.7 \\
(92.6)\end{array}$ & $\begin{array}{c}89.9 \\
(95.7)\end{array}$ & $\begin{array}{c}94.5 \\
(88.9)\end{array}$ & $\begin{array}{c}92.9 \\
(98.8)\end{array}$ & $\begin{array}{c}87.6 \\
(96.2)\end{array}$ & $\begin{array}{c}90.8 \\
(96.7)\end{array}$ & $\begin{array}{c}91.9 \\
(80.0)\end{array}$ & $\begin{array}{c}89.4 \\
(95.3)\end{array}$ \\
\hline $\mathrm{Dk} / \mathrm{HK} / \mathrm{Y} 280 / 97$ & $\begin{array}{c}81.4 \\
(88.0)\end{array}$ & $\begin{array}{c}86.5 \\
(88.0)\end{array}$ & $\begin{array}{c}88.6 \\
(85.4)\end{array}$ & $\begin{array}{c}92.8 \\
(92.6)\end{array}$ & $\begin{array}{c}90.9 \\
(94.5)\end{array}$ & $\begin{array}{c}93.4 \\
(88.9)\end{array}$ & $\begin{array}{c}89.1 \\
(97.3)\end{array}$ & $\begin{array}{c}87.0 \\
(96.3)\end{array}$ & $\begin{array}{c}88.9 \\
(96.2)\end{array}$ & $\begin{array}{c}88.5 \\
(71.1)\end{array}$ & $\begin{array}{c}84.4 \\
(95.7)\end{array}$ \\
\hline $\mathrm{Ck} / \mathrm{HK} / \mathrm{G} 9 / 97$ & $\begin{array}{c}82.0 \\
(87.5)\end{array}$ & $\begin{array}{c}86.8 \\
(87.8)\end{array}$ & $\begin{array}{c}88.3 \\
(84.5)\end{array}$ & $\begin{array}{c}91.8 \\
(92.6)\end{array}$ & $\begin{array}{c}91.0 \\
(94.9)\end{array}$ & $\begin{array}{c}93.7 \\
(90.0)\end{array}$ & $\begin{array}{c}89.4 \\
(96.7)\end{array}$ & $\begin{array}{c}86.5 \\
(95.8)\end{array}$ & $\begin{array}{c}90.7 \\
(96.5)\end{array}$ & $\begin{array}{c}91.1 \\
(77.8)\end{array}$ & $\begin{array}{c}89.8 \\
(94.9)\end{array}$ \\
\hline Ck/Kor/96323/96 & $\begin{array}{c}95.7 \\
(95.5)\end{array}$ & $\begin{array}{c}92.0 \\
(93.2)\end{array}$ & $\begin{array}{c}94.7 \\
(89.8)\end{array}$ & $\begin{array}{c}95.7 \\
(92.6)\end{array}$ & $\begin{array}{c}95.4 \\
(97.2)\end{array}$ & $\begin{array}{c}96.3 \\
(93.3)\end{array}$ & $\begin{array}{c}93.0 \\
(98.5)\end{array}$ & $\begin{array}{c}95.7 \\
(97.5)\end{array}$ & $\begin{array}{c}97.1 \\
(98.4)\end{array}$ & $\begin{array}{c}98.1 \\
(95.6)\end{array}$ & $\begin{array}{c}90.7 \\
(97.0)\end{array}$ \\
\hline $\mathrm{Ck} / \mathrm{BJ} / 1 / 94$ & $\begin{array}{c}82.8 \\
(92.5)\end{array}$ & $\begin{array}{c}87.8 \\
(89.2)\end{array}$ & $\begin{array}{c}90.1 \\
(86.7)\end{array}$ & $\begin{array}{c}93.2 \\
(94.1)\end{array}$ & $\begin{array}{c}90.4 \\
(92.9)\end{array}$ & $\begin{array}{l}94.8 \\
(91.1)\end{array}$ & $\begin{array}{c}89.6 \\
(97.0)\end{array}$ & $\begin{array}{c}87.4 \\
(96.9)\end{array}$ & $\begin{array}{c}89.6 \\
(96.7)\end{array}$ & $\begin{array}{c}91.1 \\
(76.7)\end{array}$ & $\begin{array}{c}85.2 \\
(96.4)\end{array}$ \\
\hline
\end{tabular}

quences, but a reverse relation was observed in the NS1 (except DK/ST/1605/01), NS2, M2, and PB1-F2 genes. The most similar avian influenza viruses in terms of the amino acid similarity of each gene segment are summarized in Table 4. The amino acid sequence similarities of KBNP-0028 were closest to Korean H9N2 strains in the HA, NA, M1, M2, and PB1-F2, but the NP, PA, PB1, and PB2 were closest to foreign AIV strains of various subtypes, hosts, and geographical backgrounds (Table 4).

The important amino acids at the receptor binding site (RBS) were H (183), E (190), and Q (226), and the proteolytic cleavage site possessed a single basic amino acid, ASGR. The N-linked glycan at $158 \mathrm{~N}$ was expected to be present in KBNP-0028. In contrast to compared H9N2 viruses, KBNP-0028 showed a 16 amino acid deletion (64-79 residues) at the stalk region of NA (Fig. 1; Table 5), and the selection of the deletion mutant during embryonic passages is apparent in Fig. (2). KBNP-0028 contained amino acid residues $344 \mathrm{R}$ and $466 \mathrm{~F}$ in the NA protein, and was thought to be stable at low $\mathrm{pH}$ conditions [33]. There were two NS1 types in terms of amino acid length, (230 and 217), and KBNP-0028 possessed a longer NS1 sequence. Although the biological role of residue 92 of NS1 is elusive, KBNP-0028 carried D rather than E. Other viruses possessed ESEV or EPEV as a PL motif of NS1, while the NS1 PL motifs of KBNP-0028 and SNU0028-E5 were different, GSEV (Table 5). The amino acid residues at 27, 30, and 31 of M2, and 627 of PB2 were V, A, S, and D, respectively, and KBNP-0028 did not display markers of amantadine-resistance and virulence for humans (Table 5).

Table 4. The Most Similar Avian Influenza Virus to Each Protein of KBNP-0028

\begin{tabular}{|c|l|c|}
\hline KBNP-0028 & \multicolumn{1}{|c|}{ The Most Similar Virus [Accession No.] } & Amino Acid Percent Identity \\
\hline \hline HA & A/ck/Korea/ms96/96 (H9N2) [AF203008] & $96.6 \%(541 / 560)$ \\
\hline NA & A/Chicken/Korea/99029/99 (H9N2) [AF508582] & $94.6 \%(438 / 463)$ \\
\hline NS1 & $\begin{array}{l}\text { A/duck/Nanchang/1944/1993 (H7N4) [U49493], A/mallard/Alberta/211/98 (H1N1) [AY633216], } \\
\text { ACY005497] }\end{array}$ & $93.0 \%(214 / 230)$ \\
\hline NS2 & A/WS/1933(H1N1) [U13683] & $97.5 \%(118 / 121)$ \\
\hline M1 & A/duck/UKR/1/1963(H3N8) [CY005814], A/Chicken/Korea/99029/99 (H9N2) [AF508692] & $98.4 \%(248 / 252)$ \\
\hline M2 & A/Chicken/Korea/ms96/96(H9N2) [AF203788] & $96.9 \%(94 / 97)$ \\
\hline NP & $\begin{array}{l}\text { A/Netherlands/219/03(H7N7) [AY342425], A/mallard/Postdam/178-4/83(H2N2) [DQ017489], } \\
\text { A/duck/Hong Kong/24/1976(H4N2) [CY005627] }\end{array}$ & $99.0 \%(493 / 498)$ \\
\hline PA & A/mallard duck/Alberta/331/1985(H3N6) [CY014553] & $98.9 \%(708 / 716)$ \\
\hline PB1 & $\begin{array}{l}\text { A/shorebird/DE/101/2004 (H5N7) [CY004404], A/ruddy turnstone/NJ/65/1985 (H7N3) [CY004411], } \\
\text { A/mallard duck/AST/266/1982 (H14N5) [CY005401] }\end{array}$ & $98.8 \%(748 / 757)$ \\
\hline PB1-F2 & A/Chicken/Korea/38349-p96323/96 (H9N2) [AF156425] & $\begin{array}{c}\text { A/manchang/1904/1992 (H7N1) } \\
\text { A/green-winged teal/ALB/228/1985(H7N3) [CY005407] }\end{array}$ \\
\hline PB2 & A/mallard/Albert/209/2003(H10N7) [CY004359], A/pintail/berta/84/2000(H11N9) [CY005330], $(86 / 90)$ \\
\hline
\end{tabular}


Dk/ST/1605/01

$\mathrm{Pk} / \mathrm{Chi} / \mathbf{1 / 9 7}$

Qa/HK/G1/97

Dk/HK/Y280/97

Ck/HK/G9/97

Ck/Kor/96323/96

$\mathrm{Ck} / \mathrm{BJ} / \mathbf{1} / \mathbf{9 4}$

Ck/Kor/KBNP-0028/00

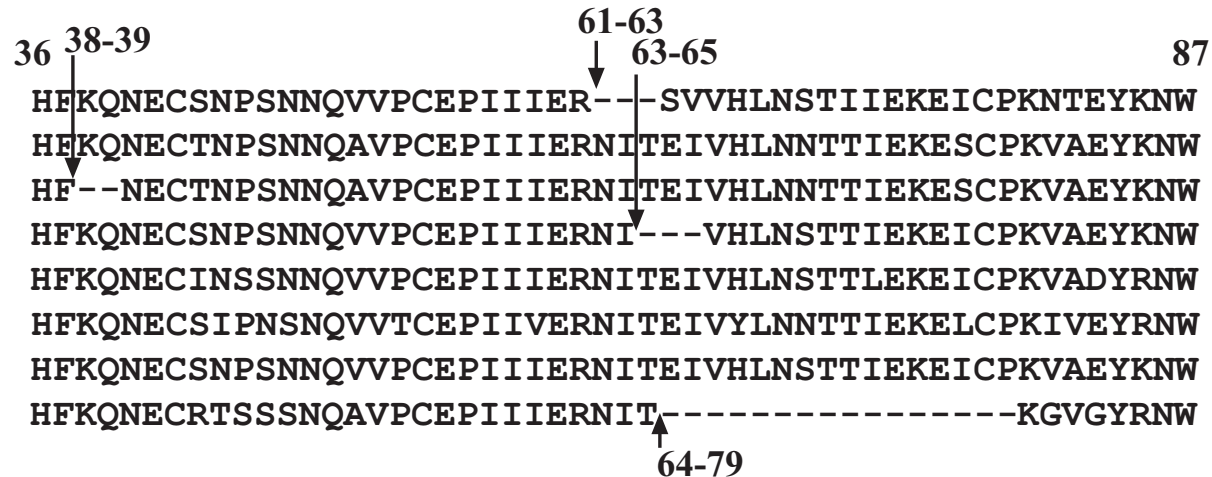

64-79

Fig. (1). Comparison of amino acid sequences of the NA2 stalk region. Deleted amino acids are represented with dashes.

\section{DISCUSSION}

The serological prevalence of the H9N2 virus in chickens has increased since 1999, and LPAI has also become enzootic in the Republic of Korea. Although the H9N2 virus is

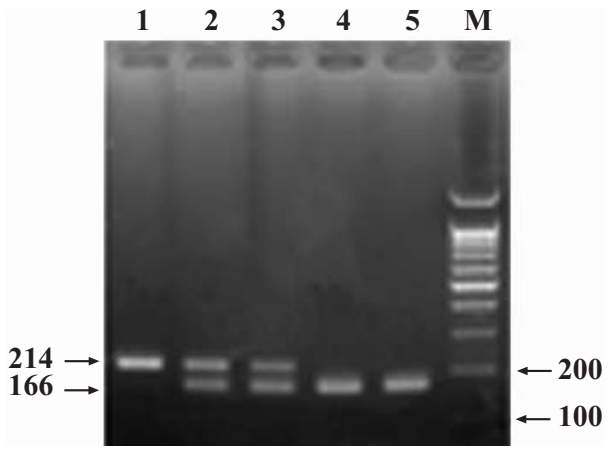

Fig. (2). Selection of deleted NA2 during the passages. Lane 1: E7 (seven times passaged virus), lane 2: E10, lane 3: E11, lane 4: E15, lane 5: E19, M: 100bp molecular weight marker. thought to be avirulent to humans, economic losses to the poultry industry and the possible appearance of mutants capable of overcoming the human host barrier cannot be ignored. To resolve this problem, a vaccine policy has been implemented by the government, but more productive, avirulent, and antigenically representative vaccine strains still need to be developed $[9,16,17]$. The early and the recurrent H9N2 viruses were divided into at least two distinct types of viruses according to the presence or absence of NGS sequon ( 3 consecutive amino acids that can serve as an attachment site for a sugar) at residues 158-160 [31]. The N-glycans in the vicinity of the receptor binding site of HA and the amino acid deletion in the stalk region of NA decrease receptor affinity and enzyme activity [34, 35]. To obtain efficient influenza virus propagation in cell lines and ECE, the balance between HA and NA is essential [17, 19-23]. The yield of vaccine virus in ECE is affected not only by the replication efficiency of virus, but also by the virulence to embryos. The rapid replication of vaccine virus with highly active HA and NA may be a burden to embryos, and may cause early embryonic mortality. High embryonic virulence may result in a decrease of the amount of allantoic fluid and an increase

Table 5. Comparison of Important Amino Acid Residues of H9N2 Viruses

\begin{tabular}{|c|c|c|c|c|c|c|c|c|c|c|}
\hline \multirow[b]{2}{*}{ Strain } & \multicolumn{3}{|c|}{ HA } & \multicolumn{2}{|c|}{ NA } & \multicolumn{3}{|c|}{ NS1 } & \multirow[b]{2}{*}{$\begin{array}{c}\text { M2 } \\
(27-30-31)\end{array}$} & \multirow{2}{*}{$\begin{array}{c}\text { PB2 } \\
\begin{array}{c}\text { Residue } \\
\text { at } 627\end{array}\end{array}$} \\
\hline & $\begin{array}{l}\operatorname{RBS}^{\mathrm{a}}(183- \\
190-226)\end{array}$ & $\begin{array}{l}\text { Cleavage } \\
\text { Site }\end{array}$ & $\begin{array}{l}158^{b} \\
\text { Glycan }\end{array}$ & $\begin{array}{l}\text { Stalk Deletion } \\
\text { Nos. of aa }\end{array}$ & $\begin{array}{c}\text { Low pH Stability } \\
(344-466)\end{array}$ & $\begin{array}{c}\text { Number } \\
\text { of aa }\end{array}$ & $\begin{array}{l}\text { Residue } \\
\text { at } 92\end{array}$ & $\begin{array}{c}\text { PL }^{\mathrm{e}} \\
\text { Motif }\end{array}$ & & \\
\hline KBNP-0028 & H-E-Q & ASGR & + & $16(64-79)$ & $\mathrm{S}^{\mathrm{c}}(\mathrm{R}-\mathrm{F})$ & 230 & $\mathrm{D}$ & GSEV & $\mathrm{S}^{\mathrm{f}}(\mathrm{V}-\mathrm{A}-\mathrm{S})$ & $\mathrm{E}$ \\
\hline SNU0028-E5 & H-E-Q & ASGR & + & - & nd & nd & nd & GSEV & nd & E \\
\hline $\mathrm{Pk} / \mathrm{Chi} / 1 / 97$ & H-E-L & RSSR & - & - & $S(R-F)$ & 230 & $\mathrm{E}$ & EPEV & $\mathrm{S}(\mathrm{V}-\mathrm{A}-\mathrm{S})$ & $\mathrm{E}$ \\
\hline $\mathrm{Qa} / \mathrm{HK} / \mathrm{G} 1 / 97$ & H-E-L & RSSR & - & $2(38-39)$ & $\mathrm{nd}^{\mathrm{d}}$ & 230 & $\mathrm{E}$ & EPEV & $\mathrm{S}(\mathrm{V}-\mathrm{A}-\mathrm{S})$ & $\mathrm{E}$ \\
\hline Dk/HK/Y280/97 & N-T-L & RSSR & - & $3(62-64)$ & $S(R-F)$ & 230 & $\mathrm{D}$ & EPEV & $\mathrm{S}(\mathrm{V}-\mathrm{A}-\mathrm{S})$ & $\mathrm{E}$ \\
\hline Ck/HK/G9/97 & N-A-L & RSSR & - & - & $S(R-F)$ & 217 & $\mathrm{D}$ & EPEV & $\mathrm{S}(\mathrm{V}-\mathrm{A}-\mathrm{S})$ & E \\
\hline Ck/Kor/96323/96 & H-E-Q & ASYR & - & - & $S(R-F)$ & 230 & $\mathrm{D}$ & ESEV & $\mathrm{S}(\mathrm{V}-\mathrm{A}-\mathrm{S})$ & $\mathrm{E}$ \\
\hline $\mathrm{Ck} / \mathrm{BJ} / 1 / 94$ & N-V-Q & RSSR & - & - & $S(R-F)$ & 217 & $\mathrm{D}$ & EPEV & $\mathrm{S}(\mathrm{V}-\mathrm{A}-\mathrm{S})$ & $\mathrm{E}$ \\
\hline $\mathrm{Dk} / \mathrm{ST} / 1605 / 01$ & N-A-L & RSSR & + & $3(62-64)$ & nd & 230 & $\mathrm{D}$ & ESEV & nd & $\mathrm{E}$ \\
\hline
\end{tabular}

${ }^{a}$ RBS, receptor binding site; ${ }^{b} \mathrm{H} 3$ numbering; ${ }^{\mathrm{c}} \mathrm{S}$, stable; ${ }^{\mathrm{d}}$ nd, not determined; ${ }^{\mathrm{e}} \mathrm{PL}$, PDZ-domain ligand; ${ }^{\mathrm{I}} \mathrm{S}$, amantadine susceptible. 
in the number of discarded ECE [14]. Thus, selection of a virus with low virulence is preferred for the development of a productive vaccine virus in an ECE-based production system. SNU0028 possessed only $158 \mathrm{~N}$-glycan, and it was less productive and more virulent to embryos than KBNP-0028, which acquired a 16 amino acid deletion of NA during passages [23]. SNU0028 may bud out more rapidly than KBNP0028 because of the low receptor affinity of HA and the high enzymatic activity of NA, and it may cause an early explosion of viral replication in the early stage of infection [21, 36]. The high NA activity may cause destruction of receptors for multiple cycles of infection on the chorioallantoic membrane in the late stage of viral replication, but may release virions from red blood cells (RBCs) and inhibitory sialoproteins in the bloodstreams and tissue fluids of embryos, resulting in efficient viral infection [35]. Therefore, the higher embryonic mortality of SNU0028 compared to KBNP-0028 can be explained. The productivity of KBNP-0028 was similar to that of PR8, and it is worth noting that PR8 also possesses an N-glycan near RBS (J04572) and a 15 amino acid deletion at the stalk of NA (NC_002018). The EID $50 / \mathrm{ml}$ of KBNP-0028 was similar to that of MS96, but it was ten times higher than that of ADL0401 [16]. The low-passaged MS96, which carries $158 \mathrm{~N}$-glycan, showed low productivity and caused relatively high embryonic mortality. The passages of MS96 through 14-day-old ECE resulted in increased HA titer and embryonic mortality, but associated genetic variations were unknown [9]. ADL0401 possesses $158 \mathrm{~N}$ glycan (DQ464352), but also has an intact stalk region of NA (DQ464353), and that can be one of the reasons that it fails to replicate to high titer. The high productivity strain, Qa/HK/G1/97 (G1, AF156378), and the low productivity strain, Ck/HK/G9/97 (G9, AF156373), carried no NGS sequon at 158-160. Only G1 has additional NGS sequons at 94-96 and 198-200. The G1 strain also has a two amino acid deletion in the stalk region of NA, while G9 contains intact NA [37]. The effects of the N-glycans at residues 94 and 198 on the replication efficiency of G1 are unknown, but the proximal location of the $198 \mathrm{~N}$-glycan to the receptorbinding pocket may decrease the receptor affinity to some extent. A Korean H9N2 vaccine strain [01310 (CE20)] which had been passaged through ECE by 20 times acquired a putative NGS sequon at 133-135 and 18-amino acid deletion in the stalk region of NA during ECE passages, and also showed apparent increase of virus titer. But the embryonic mortality within $48 \mathrm{hrs}$ increased from $30 \%$ [01310(CE5)] to $60 \%$ [01310(CE20)] during the passages [17]. In contrast to the high embryonic virulence 01310(CE20) was avirulent to SPF chickens after challenge via intravenous route. Therefore, different embryonic virulence among avian influenza viruses may support further studies to find relevant genetic markers in other genes except HA and NA genes.

The low-pH stability of NA conferred by $344 \mathrm{R}$ and $466 \mathrm{~F}$ was reported to increase the replication ability of a virus in the MDCK cell line [38]. KBNP-0028 possessed the amino acids associated with the low $\mathrm{pH}$ stability, and the high productivity may be attributed to the low $\mathrm{pH}$ stability, in part.

Although the balance of HA and NA with low activities is important, it is not essential for obtaining high productivity of influenza virus in ECE. For example, the productivity of G9 was improved by internal gene reassortment with PR8 [13]. Therefore, the high productivity of an influenza virus in
ECE may result from multigenic traits. $\mathrm{N}$-glycans can affect the antigenicity and immunogenicity of HA by shielding and masking epitopes recognized by antibodies and CD4+ $\mathrm{T}$ cells, respectively $[39,40]$. The $158 \mathrm{~N}$-glycan of the H5N1 virus is not crucial to the protective efficacy of the H5 vaccine [41], and the observation that KBNP-0028 induced a high antibody titer may also support the notion that the presence of $158 \mathrm{~N}$-glycan has less or no effect on its immunogenicity and antigenicity.

The amino acid sequences of NS1 (except DK/ST/1605/ 01), NS2, M2, and PB1-F2 genes were more variable than the respective nucleotide sequences. These differences can result from strong selection pressure during new host adaptations, but the biological effects of the amino acid changes still need to be elucidated [42]. The amino acid sequence similarities of KBNP-0028 were closest to Korean H9N2 strains in HA, NA, M1, M2, and PB1-F2, but NS2, NP, PA, $\mathrm{PB} 1$, and PB2 were closest to foreign AIV strains of various subtypes, hosts, and geographical backgrounds. The natural avian reservoirs of $\mathrm{H} 9$ viruses are known to be shorebirds and gulls, and interregional transmission of the internal protein gene segments between North American and Eurasian migratory ducks has been reported $[43,44]$. Therefore, the relatively high similarities of KBNP-0028 (M1, NP, PA, $\mathrm{PB} 1$, and PB2) to various subtypes from wild birds of Europe, Hong Kong, and Alberta can be expected, but relatively low similarities of NA and NS1 to corresponding genes in the GenBank reflect that unisolated or isolated but unsequenced viruses remain present in the pool of avian influenza viruses.

The safety of avian influenza vaccine candidates to mammalian hosts is one of the most important prerequisites for good vaccines. The Q226L mutation in the RBS increases and decreases to nearly zero in terms of the affinity of HA to oligosaccharides that contain the Neu5Ac- $\alpha 2$, 6Gal and Neu5Ac- $\alpha 2$, 3-Gal, respectively. The additional E190A or E190T decreases the affinity of HA to Neu5Ac$\alpha 2,6-G a l$ without changing the affinity to Neu5Ac- $\alpha 2,3-\mathrm{Gal}$ [45]. KBNP-0028 carried 190E and 226Q, and it may bind strongly to Neu5Ac- $\alpha 2$, 3-Gal. Ck/Kor/96323/96 was reported to bind to Neu5Ac- $\alpha 2,6-G a l$ of pig $\alpha 2-$ macroglobulin, and KBNP-0028 is likely to bind to Neu5Ac$\alpha 2$, 6-Gal because of the similarity of its RBS to Ck/Kor/96323/96 [45]. The binding of HA to Neu5Ac- $\alpha 2,6-$ Gal may render the virus capable of replicating in humans. However, KBNP-0028 can be effectively inhibited by sialoproteins in the body fluids [46]. The number of basic amino acids at the HA cleavage site affects the virulence of the influenza A virus. HA needs to be cleaved by endogenous or exogenous proteolytic enzymes for full biological activity. The oligobasic motif, arg-X-lys/arg-arg (R-X-K/R-R), of HA in the influenza virus and the fusion protein of Newcastle disease virus is recognized by the mammalian endogenous proteolytic enzyme, furin/PACE. The monobasic motif, R$\mathrm{X}-\mathrm{X}-\mathrm{R}$, was cleaved with a ten-fold lower efficiency than R$\mathrm{X}-\mathrm{K} / \mathrm{R}-\mathrm{R}$, but was cleaved at a similar rate as $\mathrm{R}-\mathrm{X}-\mathrm{K} / \mathrm{R}-\mathrm{R}$ by another endogenous proteolytic enzyme, PC1/PC3, in endocrine cells [47]. None of the endogenous proteolytic enzymes were capable of cleaving the X-X-X-R motif [47-49]. Therefore, KBNP-0028 may depend completely on exogenous proteolytic enzymes for viral replication, but further studies are needed to clarify the differences in tissue tropism 
and virulence mediated by the motifs. The NS1 of KBNP0028 was composed of 230 amino acids, while $\mathrm{Ck} / \mathrm{HK} / \mathrm{G} 9 / 97$ and $\mathrm{Ck} / \mathrm{BJ} / 1 / 94$ have a shorter NS1, at 217 amino acids. The NS1 of KBNP-0028 contained an intact RNA-binding domain, an effector domain that prevented the export of RNA from the nucleus with host nuclear protein, and two nuclear localization signals $[50,51]$. The length of NS1 is variable among influenza A viruses, and its biological effect remains unknown [52]. Recently, a PL motif was identified at the carboxyl terminal of NS1, and it was suggested to be a potential determinant of virulence [29]. The highly virulent isolates from the pandemic in 1918, the 1997-1999 outbreaks in Hong Kong, and the 2003-2004 outbreaks in Hong Kong, Vietnam, and Thailand possessed KSEV, EPEV, and ESEV motifs, respectively, and they bound to various PDZ domains with different affinity. All of the H9N2 viruses compared in the present study and Korean strains (AY862662-AY862670, AF156482, and AF508713) have an EPEV or ESEV motif, but KBNP-0028 has a unique motif, GSEV. The binding affinity of the GSEV motif to the PDZ domain needs to be determined, but it is worth noting that PR8 contains an RSEV motif. According to the residues of PB2 (627E) and M2 (27V-30A-31S), KBNP-0028 does not display markers of virulence for humans and resistance to amantadine $[25,26,30]$. In conclusion, KBNP-0028 is productive in an ECE-based vaccine production system, is sufficiently immunogenic and antigenically representative of contemporary H9N2 viruses in the Republic of Korea. Therefore, KBNP-0028 is a promising vaccine candidate for prevention of the LPAI in the Republic of Korea.

\section{ACKNOWLEDGEMENTS}

This work was supported by the Regional Industrial Technology Development Program of the Ministry of Commerce, Industry and Energy, and a Korea Research Foundation Grant (KRF-2006-005-J02901).

\section{REFERENCES}

[1] Webster RG, Bean WJ, Gorman OT, Chambers TM, Kawaoka Y. Evolution and ecology of influenza A viruses. Microbiol Rev 1992; 56(1): 152-79.

[2] Fouchier RA, Munster V, Wallensten A, et al. Characterization of a novel influenza A virus hemagglutinin subtype (H16) obtained from black-headed gulls. J Virol 2005; 79(5): 2814-22.

[3] Papparella V, Fioretti A, Menna LF. Avian influenza: current situation in Germany. In: Proceedings of the Joint second annual meetings of the National Newcastle Disease and Avian Influenza Laboratories of Countries of the European Union. Brussels, Belgium 1994; pp. 14-5.

[4] Campbell G. Report of the Irish national reference laboratory for 1996 and 1997. In: proceedings of the Joint $4^{\text {th }}$ annual meetings of the National Newcastle Disease and Avian Influenza Laboratories of Countries of the European Union. Brussels, Belgium 1997: 13.

[5] Halvorson DA, Frame DD, Friendshuh AJ, Shaw DP. Outbreaks of low pathogenicity avian influenza in USA. In: Proceedings of the $4^{\text {th }}$ International symposium on avian influenza. Athens, GA: US Animal Health Association 1997; pp. 36-46.

[6] Naeem K, Ameerullah M, Manvell RJ, Alexander DJ. Avian influenza A subtype H9N2 in poultry in Pakistan. Vet Rec 1999; 145(19): 560.

[7] Lee CW, Song CS, Lee YJ, et al. Sequence analysis of the hemagglutinin gene of H9N2 Korean avian influenza viruses and assessment of the pathogenic potential of isolate MS96. Avian Dis 2000; 44(3): 527-35.

[8] Nili H, Asasi K. Natural cases and an experimental study of H9N2 avian influenza in commercial broiler chickens of Iran. Avian Pathol 2002; 31(3): 247-52.
[9] Lee CW. Molecular and pathogenic characteristics of Korean isolates of avian influenza virus (H9N2). (Thesis paper) Seoul National University 1998.

[10] Banks J, Speidel C, Harris PA, Alexander DJ. Phylogenetic analysis of influenza A viruses of $\mathrm{H} 9$ hemagglutinin subtype. Avian Pathol 2000; 29(4): 353-60.

[11] Bano S, Naeem K, Malik SA. Evaluation of pathogenic potential of avian influenza virus serotype H9N2 in chickens. Avian Dis 2003; 47(Suppl 4): 817-22.

[12] Kishida N, Sakoda Y, Eto M, Sunaga Y, Kida H. Co-infection of Staphylococcus aureus or Haemophilus paragallinarum exacerbates H9N2 influenza A virus infection in chickens. Arch Virol 2004; 149(11): 2095-104.

[13] Chen H, Subbarao K, Swayne D, et al. Generation and evaluation of a high-growth reassortant H9N2 influenza A virus as a pandemic vaccine candidate. Vaccine 2003; 21(17-18): 1974-9.

[14] OIE. Manual of diagnostic tests and vaccines for terrestrial animals. Avian influenza. Chapter 2.7.12; $5^{\text {th }}$ ed, 2005.

[15] WHO. Recommendations for the production and control of influenza vaccine (inactivated). WHO Technical report series No. 927, 2005.

[16] Lee JS, Ha DH, Kim JE, Ha BD, Mo IP. Evaluation on immunogenicity and safety of avian influenza isolate (ADL0401) as a candidate for the killed vaccine against low-pathogenic avian influenza. Korean J Poult Sci 2005; 32(2): 113-23.

[17] Choi JG, Lee YJ, Kim YJ, et al. An inactivated vaccine to control the current H9N2 low pathogenic avian influenza in Korea. J Vet Sci 2008; 9(1): 67-74.

[18] Paulson JC. Interactions of animal viruses with cell surface receptors. In: Conn M, Ed. The Receptors, Academic Press: Orlando, FL 1985; Vol. 2: pp. 131-219.

[19] Matrosovich MN, Gambaryan AS, Teneberg S, et al. Avian Influenza A viruses differ from human viruses by recognition of sialyloligosaccharides and gangliosides and by a higher conservation of the HA receptor-binding site. Virology 1997; 233(1): 224-34.

[20] Mitnaul LJ, Matrosovich MN, Castrucci MR, et al. Balanced hemagglutinin and neuraminidase activities are critical for efficient replication of influenza A virus. J Virol 2000; 74(13): 6015-20.

[21] Wagner R, Wolff T, Herwig A, Pleschka S, Klenk H. Interdependence of hemagglutinin glycosylation and neuraminidase as regulators of influenza virus growth: a study by reverse genetics. J Virol 2000; 74(14): 6316-23.

[22] Egorov A, Brandt S, Sereinig S, et al. Transfectant influenza A viruses with long deletions in the NS1 protein grow efficiently in Vero cells. J Virol 1998; 72(8): 6437-41.

[23] Kwon HJ, Cho SH, Ahn YJ, Kim SJ. Characterization of a highly productive H9N2 subtype avian influenza virus (SNU0028-KBNP). The $49^{\text {th }}$ Annual Meeting of the Korean Society of Veterinary Science 2005; 45(3): 60 (Abstract in Korean).

[24] Seo SH, Hoffmann E, Webster RG. Lethal H5N1 influenza viruses escape host anti-viral cytokine responses. Nat Med 2002; 8(9): 9504.

[25] Subbarao EK, London W, Murphy BR. A single amino acid in the PB2 gene of influenza A virus is a determinant of host range. J Virol 1993; 67(4): 1761-4.

[26] Shinya K, Hamm S, Hatta M, Ito H, Ito T, Kawaoka Y. PB2 amino acid at position 627 affects replicative efficiency, but not cell tropism, of Hong Kong H5N1 influenza A viruses in mice. Virology 2004; 320(2): 258-66.

[27] Chen W, Calvo PA, Malide D, et al. A novel influenza A virus mitochondrial protein that induces cell death. Nat Med 2001; 7(12): 1306-12.

[28] Sheng M, Sala C. PDZ domains and the organization of supramolecular complexes. Annu Rev Neurosci 2001; 24: 1-29.

[29] Obenauer JC, Denson J, Mehta PK, et al. Large-scale sequence analysis of avian influenza isolates. Science 2006; 311(5767): 1576-80.

[30] Ilyushina NA, Govorkova EA, Webster RG. Detection of amantadine-resistant variants among avian influenza viruses isolated in North America and Asia. Virology 2005; 341(1): 102-6.

[31] Kwon HJ, Cho SH, Kim MC, Ahn YJ, Kim SJ. Molecular epizootiology of recurrent low pathogenic avian influenza by H9N2 subtype virus in Korea. Avian Pathol 2006; 35(4): 309-15.

[32] Hoffmann E, Stech J, Guan Y, Webster RG, Perez DR. Universal primer set for the full-length amplification of all influenza A viruses. Arch Virol 2001; 146(12): 2275-89. 
[33] Takahashi T, Suzuki T, Kazuya IP, Hidari J, Miyamoto D, Suzuki Y. A molecular mechanism for the low-pH stability of sialidase activity of influenza A virus N2 neuraminidases. FEBS Lett 2003; 543(1-3): 71-5.

[34] Ohuchi M, Ohuchi R, Feldmann A, Klenk HD. Regulation of receptor binding affinity of influenza virus hemagglutinin by its carbohydrate moiety. J Virol 1997; 71(11): 8377-84.

[35] Castrucci M, Kawaoka Y. Biologic importance of neuraminidase stalk length in influenza A virus. J Virol 1993; 67(2): 759-64.

[36] Baigent SJ, McCauley JW. Glycosylation of haemagglutinin and stalk-length of neuraminidase combine to regulate the growth of avian influenza viruses in tissue culture. Virus Res 2001; 79: 17785.

[37] Liu JH, Okazaki K, Shi WM, Wu QM, Mweene AS, Kida H. Phylogenetic analysis of neuraminidase gene of H9N2 influenza viruses prevalent in chickens in China during 1995-2002. Virus Genes 2003; 27(2): 197-202.

[38] Suzuki T, Takahashi T, Guo CT, et al. Sialidase activity of influenza $A$ virus in an endocytic pathway enhances viral replication. $\mathbf{J}$ Virol 2005; 79(18): 11705-15.

[39] Skehel JJ, Stevens DJ, Daniels RS, et al. A carbohydrate side chain on hemagglutinins of Hong Kong influenza viruses inhibits recognition by a monoclonal antibody. Proc Natl Acad Sci USA 1984; 81(6): 1779-83.

[40] Wiley DC, Skehel JJ. The structure and function of the hemagglutinin membrane glycoprotein of influenza virus. Annu Rev Biochem 1987; 56: 365-94.

[41] Hoffmann E, Lipatov AS, Webby RJ, Govorkova EA, Webster RG. Role of specific hemagglutinin amino acids in the immunogenicity and protection of H5N1 influenza virus vaccines. Proc Natl Acad Sci USA 2005; 102(36): 12915-20.

[42] Lin YP, Shaw M, Gregory V, et al. Avian-to-human transmission of H9N2 subtype influenza A viruses: relationship between H9N2 and H5N1 human isolates. Proc Natl Acad Sci USA 2000; 97(17): 9654-8.

[43] Kawaoka Y, Chambers TM, Sladen WL, Webster RG. Is the gene pool of influenza viruses in shorebirds and gulls different from that in wild ducks? Virology 1988; 163(1): 247-50.

[44] Liu JH, Okazaki K, Bai GR, Shi WM, Mweene A, Kida H. Interregional transmission of the internal protein genes of $\mathrm{H} 2$ influenza virus in migratory from North America to Eurasia. Virus Genes 2004; 29(1): 81-6.

[45] Matrosovich MN, Krauss S, Webster RG. H9N2 influenza A viruses from poultry in Asia have human virus-like receptor specificity. Virology 2001; 281(2): 156-62.

[46] Gottschalk A, Belyavin G, Biddle F. Glycoproteins as influenza virus hemagglutinin inhibitors and as cellular virus receptors, Glycoproteins, their composition, structure and function, part A. In: Gottschalk A, Ed. Amsterdam, Elsevier 1972; pp. 1082-96.

[47] Nakayama K, Watanabe T, Nakagawa T, et al. Consensus sequence for precursor processing at mono-arginyl sites. J Biol Chem 1992; 267(12): 16335-40.

[48] Horimoto T, Nakayama K, Smeekens SP, Kawaoka Y. Proproteinprocessing endoproteases PC6 and furin both activate hemagglutinin of virulent avian influenza viruses. J Virol 1994; 68(9): 6074-8.

[49] Walker JA, Molloy SS, Thomas G, et al. Sequence specificity of furin, a proprotein-processing endoprotease, for the hemagglutinin of a virulent avian influenza virus. J Virol 1994; 68(2): 1213-8.

[50] Greenspan D, Palese P, Krystal M. Two nuclear location signals in the influenza virus NS1 nonstructural protein. J Vriol 1988; 62(8): 3020-6.

[51] Qiu Y, Krug RM. The influenza virus NS1 protein is a poly(A)binding protein that inhibits nuclear export of mRNAs containing poly(A). J Vriol 1994; 68(4): 2425-32.

[52] Parvin JD, Young JF, Palese P. Nonsense mutations affecting the lengths of the NS1 nonstructural proteins of influenza A virus isolates. Virology 1983; 128(2): 512-7.

This is an open access article licensed under the terms of the Creative Commons Attribution Non-Commercial License (http://creativecommons.org/licenses/by$\mathrm{nc} / 3.0 /$ ) which permits unrestricted, non-commercial use, distribution and reproduction in any medium, provided the work is properly cited. 